\title{
A Technique For Continuous Evaluation Of Student Performance In Two Different Domains: Structural Engineering And Computer Information Technology
}

Niranjan Desai, Purdue University Northwest, USA

George Stefanek, Purdue University Northwest, USA

\begin{abstract}
Student access to the Internet has made it much easier for students to find solutions to traditional homework problems online and thereby has made this traditional assessment method of monitoring student progress and gauging the assimilation of knowledge in engineering and technology courses less reliable. This paper presents an in-class, group-based quiz technique where students are quizzed typically on a weekly basis on material presented during the same week in lecture, but before doing any homework. Homework is typically not graded or its impact reduced on its percentage impact on the final class grade, whereas the quizzes are assigned a higher percentage impact on the final grade. Mid-term and final exams are based or derived from the homework assignments. Since students have not usually had any time to study the new material, they can work in groups of typically two or three students and if they get stuck, they have the option of asking the instructor for hints to prevent them from being stuck. Quizzes are graded in real-time during the class and provide the instructor with continuous, week to week, assessment as to a student's progress. The study found that the use of this quiz technique creates a more interactive experience between students, between the student and the instructor, and reduces the possibility of plagiarism on homework assignments.
\end{abstract}

Keywords: In-Class Quiz; Assessment; Group-Based Quiz

\section{INTRODUCTION}

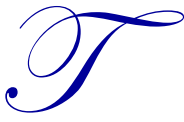

raditionally, evaluation of student performance in the classroom involved assigning weekly homework assignments, semester-long projects, conducting examinations, and holding arbitrary pop quizzes. Amongst these methods, homework assignments are a traditional indicator of a student's continuous learning of the subject matter. Traditionally, performance on homework assignments reflects the level of understanding that the student has of the material that is covered in the classroom usually on a weekly basis. Homework assignments help an instructor gauge the consistency of the student's effort. According to Kitsantas \& Zimmerman (2009), this is an essential aspect of classroom education because it was shown to instill a work ethic based upon the principles of daily effort, consistency, and dedication from the student as opposed to doing substantial amounts of work just before a deadline. Projects, exams, and quizzes are an end-product of the accumulated effort by a student over the semester but do not necessarily reflect the continuous acquisition of knowledge by the student during the semester.

Based on personal experience and upon the experience of other instructors like Gross (2011), it was observed that a certain percentage of students tend to copy from each other or solution manuals on the Internet while solving homework assignments. According to Evering \& Moorman (2012), ubiquitous Internet access makes it possible for students to discover information and problem solutions that in the past would have been difficult to find. Regular homework assignments served as an excellent tool for the continuous evaluation of student performance before the Internet was available to students, but with the onset of the Internet have made it possible for students to gain access 
to solutions online, thereby enabling them to use these solutions in their homework assignments. Internet access has made it extremely challenging for professors to ensure that students do their work. One way to work around this problem is for each instructor to create their set of unique assignment problems, whose solutions are not available online. Developing assignment problems is an extremely time consuming and tedious process for instructors, and involves the rigor of creating reasonable and realistic problems that make sense, year after year. Additionally, solutions to these problems also need to be developed. Consequently, to circumvent the problem of student cheating on homework assignments, we have developed a continuous classroom evaluation technique which consists of administering weekly quizzes during classroom hours which allow students to work in groups and to ask for hints from the instructor. Working on quiz problems in the classroom creates an environment where it is very challenging for students to plagiarize material and provides the instructor with a tool to obtain a continuous and regular assessment of student performance and understanding of the material covered in class. Furthermore, the flexibility of working in groups and interacting with the instructor reduces the need to plagiarize material.

In this investigation, we expanded upon an initial pilot study by Desai and Stefanek (2016) that involved the application of the proposed quiz technique to structural engineering classes (within the department of civil engineering) by applying it to a different area of study: computer programming, within the Department of Computer Information Technology. The application of this technique in these disparate domains illustrates the broad scope of which this continuous evaluation technique is applicable. The nature of the problems that students were tested upon was different in the structural engineering classes and the computer programming classes. Hence, the current paper includes some examples of the quiz problems contained in both structural engineering courses, as well as computer programming courses.

\section{PURPOSE OF THE STUDY}

The purpose of this study is to:

1. Demonstrate that the proposed quiz technique has a broad scope of application and can be used across diverse areas of study within the engineering and technology fields.

2. Present a technique that can be used for the continuous evaluation of the acquisition of knowledge by students in the classroom and thereby reduce the occurrence of plagiarism that occurs in the traditional homework-based method of continuous evaluation.

3. Create a more interactive classroom experience as compared to the traditional lecture.

4. Demonstrate that the proposed quiz technique which tests students on course material with little or no preparatory time, does not decrease student performance in the class as measured by the overall final grade percentage in the course at the end of the semester.

Since the in-class quizzes discussed in this paper did not give students much preparation time, the authors were concerned that the quizzes could adversely impact students' grades. Also, the impact of traditional homework on the final grade was either eliminated or reduced because of the addition of the new quiz technique. Hence, it was desired to compare average student final grade percentages before and after the incorporation of the quiz technique into various courses, to demonstrate that average student performance did not decline while having the benefits discussed above.

\section{SIGNIFICANCE OF THE STUDY}

Based upon the discussion in the "Literature Review" in the next section, the inclusion of regular quizzes in the classroom had a positive impact on student performance. While quizzes were found to be beneficial to students, this study investigated the continuous assessment of students' knowledge by using weekly, group-based quizzes that were completed in the classroom and permitted open interaction with the instructor. The approach is unique in the following ways:

1. Interaction with the instructor is permitted. Awareness of the importance of the effect of an interactive classroom environment on student retention is already well accepted. Thus far, it has been attempted to make the classroom environment more interactive to increase student retention in STEM programs. 
According to Drew (2011), "The Association of American Universities, which represents 61 of the largest research institutions, announced a five-year initiative to encourage faculty members in the STEM fields to use more interactive teaching techniques." The instructor may give the concerned student(s) hints/guidance, if necessary, since all the course material that is in the quiz is presented during the same week as the lecture and students do not typically have time to prepare or do any homework. Interaction with the instructor eliminates the chance of plagiarism and immediately reinforces what was learned during that week's lecture. An important goal of this study was to develop a means of continuous evaluation of the student's acquisition of knowledge by eliminating the effect of plagiarism that occurs in the traditional homework based approach. Another benefit of this technique which allows for communication with the instructor is that it helps build a rapport between the students and the instructor and creates an interactive classroom experience.

2. Weekly homework assignments are distributed but are not typically graded. The exams are closely based on the homework, thereby giving the students an incentive to work on the homework assignments independently, even though the homework is not graded. It had been observed, that students who do not work on the homework problems before the first exam, changed their attitude and worked on the homework problems after the first exam since they found that the exam problems were closely linked to the homework. Once again, this minimizes any component of their grade being dependent upon work that has the possibility of being plagiarized. The programming courses had the homework graded, but reduced their percentage impact of this component on the final class grade. The goal of this evaluation is to improve upon the approach used to evaluate the "continuous" acquisition of knowledge.

3. The proposed technique has been applied to two different fields. The results of this study can be used to support its application in multiple domains encompassing different areas of both engineering and technology.

\section{LITERATURE REVIEW}

Arteaga \& Vinken (2013) conducted a pilot study in which quizzes were used with mechanical engineering students. The purpose of the quizzes was to help the students understand the subject matter better by repeating important course material, giving instantaneous feedback and creating an environment where students can learn and exchange ideas with their peers. Students were given a half point bonus in addition to their exam score if they completed $55 \%$ of all the quiz questions correctly. The pilot study was used to ascertain the effectiveness of this quiz-based approach, which was gauged by determining the number of students that passed the course on their first attempt, and additionally via student feedback obtained through a questionnaire. The first-time pass rate of students in the pilot study groups did, on average, increase significantly in comparison to groups in which the quizzes were not used. Additionally, feedback obtained via the questionnaire demonstrated that students found this approach to be beneficial in identifying gaps in their knowledge. Hence, Arteaga \& Vinken concluded that the pilot study was considered effective.

Balter, Enström, \& Klingenberg (2013) conducted short online quizzes that incorporated standard questions having binary responses (right/wrong) during the initial period of a course. The purpose of the quizzes was to assist students in gauging their comprehension of fundamental ideas in the course. Additionally, the short online quizzes encouraged good study habits. A study was conducted to determine whether the quiz approach was beneficial to students' learning. Student feedback was obtained via surveys and interviews. Based on feedback from the surveys it was concluded that the study which incorporated short quizzes which used generic questions with binary responses had positive effects when administered early in courses.

Faraji (2012) investigated the implementation of weekly quizzes in a chemical engineering program. The study replaced traditional weekly homework assignments with weekly paper quizzes. A comparison was made between the performance of students completing the weekly quizzes and those completing traditional weekly homework assignments. The comparisons showed that the quiz-based learning approach improved students' learning in both lower division and upper division classes. The results demonstrated the enhanced effectiveness of in-class quizzes in assessing students' continuous acquisition of knowledge in comparison to traditional homework assignments. 
Hannah, James, \& Williams (2014) used computer-aided assessment in two first-year engineering mathematics courses with weekly quizzes that provided students with an opportunity to evaluate their performance. The majority of students used the assessment until they achieved very high (>90\%) quiz scores. However, the quizzes did not improve the final exam performance.

Shafiq \& Siddiquah (2011) investigated the use of classroom quizzes to improve student learning outcomes. They compared the effect of quizzes on the results of the mid-term and final exams on an experimental and control group of students. The results revealed that the experimental group outperformed the control group significantly on both the midterm and final exams thereby supporting the use of in-class quizzes to improve student learning outcomes.

Shorter \& Young (2011) designed a pilot study to determine whether a continuous assessment method (daily in-class quizzes), cumulative assessment (online homework) or project-based learning best-predicted student learning in an undergraduate mathematics course. Each of these methods was compared to post-test scores, and it was found that continuous assessment (daily quizzes) best-predicted students' post-test scores. The results of this investigation showed the benefit of conducting in-class quizzes.

\section{LIMITATIONS OF THE STUDY}

There was a total of 278 students that participated in the study. All the students were attending a regional campus in the Midwest. During the fall of 2016, two regional campuses were combined into a single university which allowed for students from both campuses to participate starting in fall of 2016. The study was limited to courses in the Department of Mechanical and Civil Engineering and the Department of Computer Information Technology and Graphics.

\section{METHODS}

\section{Participants}

A pilot study was conducted where students were evaluated using the proposed "in-class, group-based quiz" technique for continuous student evaluation. The study was conducted to determine the efficacy of the "in-class, group-based quiz" technique.

The study consisted of applying the "in-class, group-based quiz" technique at the undergraduate level over a period of three years. Students from the departments of civil engineering, electrical engineering, mechanical engineering, and computer information technology participated in the pilot study. The number of students that participated in the study was a total of 278 students. The details of the course participation are presented in Table 1. 
Table 1. Pilot Study Course Description

\begin{tabular}{|c|c|c|c|c|c|c|}
\hline Course & Session & Year/s & Department $^{1}$ & Major $^{2}$ & $\begin{array}{l}\text { Number of } \\
\text { Students }\end{array}$ & $\begin{array}{c}\text { Average Age, } \\
\text { Location }\end{array}$ \\
\hline Statics & Fall & $\begin{array}{c}2013,2014, \\
2015,2016\end{array}$ & $\mathrm{CE}^{3}, \mathrm{ME}^{4}$ & $\mathrm{CE}, \mathrm{ME}, \mathrm{EE}^{5}$ & 182 & $19, \mathrm{MW}^{6}$ \\
\hline $\begin{array}{l}\text { Mechanics of } \\
\text { Materials }\end{array}$ & Fall & 2013 & $\mathrm{ME}$ & $\mathrm{CE}, \mathrm{ME}$ & 19 & 20-21, MW \\
\hline $\begin{array}{l}\text { Elementary Structural } \\
\text { Analysis }\end{array}$ & Fall & $\begin{array}{c}2013,2014 \\
2015\end{array}$ & $\mathrm{CE}$ & $\mathrm{CE}$ & 7 & 20-21, MW \\
\hline Steel Design & Spring & 2014,2015 & $\mathrm{CE}$ & $\mathrm{CE}$ & 8 & 20-21, MW \\
\hline $\begin{array}{l}\text { Reinforced Concrete } \\
\text { Design }\end{array}$ & Spring & 2014,2015 & $\mathrm{CE}$ & $\mathrm{CE}$ & 6 & 20-21, MW \\
\hline $\begin{array}{l}\text { Advanced Structural } \\
\text { Analysis }\end{array}$ & Spring & 2014,2015 & $\mathrm{CE}$ & $\mathrm{CE}$ & 6 & 20-21, MW \\
\hline $\begin{array}{l}\text { Structural Dynamics } \\
1\end{array}$ & Fall & 2014 & $\mathrm{CE}$ & $\mathrm{CE}$ & 3 & 22, MW \\
\hline $\begin{array}{l}\text { Structural Dynamics } \\
2\end{array}$ & Spring & 2015 & $\mathrm{CE}$ & $\mathrm{CE}$ & 2 & 22, MW \\
\hline $\begin{array}{l}\text { Introduction to } \\
\text { Object-Oriented } \\
\text { Programming }\end{array}$ & Spring & 2016 & CITG & CITG & 20 & 18-20, MW \\
\hline $\begin{array}{l}\text { Introduction to } \mathrm{C}++ \\
\text { Language } \\
\text { Programming }\end{array}$ & Spring & 2016 & CITG & CITG & 34 & 19-25, MW \\
\hline $\begin{array}{l}\text { Operating Systems } \\
\text { Tech }\end{array}$ & Fall & 2016 & CITG & CITG & 23 & 18-20, MW \\
\hline
\end{tabular}

1: This refers to the department within the school of engineering and technology that offered the concerned course

2: This refers to the major of the students that participated in the study by enrolling in the offered course

3: $\mathrm{CE}=$ Civil Engineering

4: $\mathrm{ME}=$ Mechanical Engineering

5: $\mathrm{EE}=$ Electrical Engineering

6: $\mathrm{MW}=$ Midwest, USA

7. $\mathrm{CITG}=$ Computer Information Technology

\section{Scope of Data Analysis}

The scope of the analysis of the data collected during the study included: 1) an analysis of survey-based feedback from the students that participated in the study, and 2) an analysis of the end-of-semester grades between classes that used the quiz approach and those that did not use it. Appendix A contains the survey, and Appendix B contains the grade comparison results.

\section{Procedure - Engineering Courses}

This section focuses on the methodology used to conduct the "in-class, group-based quizzes." This section provides the reader with a step-by-step, detailed description of the process involved in the effective and efficient execution of this approach. The process involves the following steps:

1. Divide the class into groups of 2-3 students, depending on the size of the class. The group should be the same throughout the semester. The instructor can adjust the group based on attrition or group dynamics.

2. Conduct a weekly quiz in the classroom. The in-class quizzes contribute to approximately $15-20 \%$ of the final grade. Typically, the quiz should contain anywhere between one to three basic questions that cover the fundamental concepts discussed in class during that week. The problems should be judiciously selected so that they are layered (i.e., a single problem covers more than one concept, starting from the more basic ones to the more advanced ones). By doing this, not as many questions are needed and yet, most of the week's concepts are covered. By grading the in-class quizzes in class or on the same day, the instructor has a better idea of the depth of each student's understanding of the 
subject matter taught during the week. Consequently, the instructor can spend less time in the following class repeating any material that the students did not properly understand in the in-class quiz. Also, if only one or two students are weak in a certain area, the instructor can organize a meeting with them to personally clarify the material instead of spending class time speaking to them. By doing so, both the instructor as well as the student get a real-time understanding of progress and grasp of the study material. An additional benefit is that this is a personalized process, as compared to handing in homework assignments which are a more impersonal approach for performance evaluation.

3. The quiz is administered during the last 20-30 minutes of the last class during the week. The time to take the quiz is flexible. If the students are unable to finish the quiz in class, then they can complete it shortly after class and submit it to the instructor. The quizzes are not administered to place students under the pressure of a deadline or to produce results in a short time. Rather, the goal is to test whether they individually have a basic understanding of new concepts discussed in class during the week. The time taken to solve the problems may vary for different students, depending on their abilities.

4. Students are freely permitted to ask the instructor for guidance if they encounter an obstacle in solving the problem(s). The instructor can provide them with an overview or hint to prevent the student from staying stuck.

5. The students are free to communicate with each other within the group. Communication with their peers increases the exchange of ideas between students and improves their collaborative skills. Students that have questions will benefit from the fact that they are being taught the correct approach to solve the problem. There is also the added benefit that students are learning from a peer, which may encourage them to question each other more freely. Fellow students that are currently in the process of undergoing the same learning curve might be able to understand each other's perspectives and questions better. Additionally, teaching a fellow student within the group helps to crystallize the understanding of the subject matter for the student that is teaching the material because the act of teaching is considered to be an excellent way to master subject matter. Thus, overall, most students in the group serve to benefit by this approach.

6. The quizzes must be done in class or shortly thereafter, but cannot be done at home. Requiring the quizzes to be done in class ensures regular attendance. Additionally, students feel motivated to be mentally present and focused during the lecture, since they know that they will be tested on the material during the same week.

7. The mid-term and final exams are directly based on the homework assignments and students are explicitly told this fact. This gives students an incentive to complete the homework assignments which are not typically graded. By regularly doing the homework assignments, the students are preparing themselves for the mid-term and final exams. If a student chooses not to do the weekly homework assignments, then their performance on the mid-term and final exams may decrease.

\section{Procedure - Computer Information Technology}

This section focuses on the methodology employed to conduct the "in-class quizzes" in computer programming courses. The process involves the following steps:

1. Divide the class into groups of 2-3 students, depending on the size of the class. The group should be the same throughout the semester. The instructor can adjust the group based on attrition or group dynamics.

2. Conduct a weekly quiz in the computer laboratory. The in-class quizzes contribute to approximately $15-20 \%$ of the final grade. Typically, the quiz contains one programming problem that covers the programming concepts discussed in class during that week. The computer programming quizzes differ from the engineering quizzes in that there is typically not enough time to do more than one programming problem since each problem needs to be fully coded and debugged. This technique differs from most conventional programming quizzes where the student is asked to write a segment of code by hand, in response to one or more simple programming questions.

3. The quiz is administered during the last 20-45 minutes of the last class of the week - the lab portion of the class. The time to take the quiz is flexible. All students must attempt to finish the quiz in class which is graded in class by the instructor by checking each student's code and whether their code 
executes properly.

4. Students are freely permitted to ask the instructor for guidance if they encounter an obstacle in solving the programming problem. The instructor can provide the student with hints to prevent the student from staying stuck.

5. Students are free to communicate with each other within the group.

6. Quizzes must be done during class hours on lab computers.

The mid-term and final exam problems are directly based or derived from the programming homework problems.

\section{Sample Quiz Problems - Engineering}

This section contains sample problems that were included in quizzes conducted in engineering courses to provide the reader with a representative example of the type of problems and level of difficulty of the problems that students were expected to solve. The problems attempted to cover the basic concepts discussed in the lecture during the week of the quiz. Each student was handed a copy of the quiz which consisted typically of 2-3 problems that varied from low to intermediate to high levels of difficulty. The goal of the quiz problems was to test whether the students knew which concept to apply, which equation(s) to use, and how to perform the analysis to get the correct answers. Course: Statics

Topics of discussion during the week: 2D Force vectors, 2D force resultants (magnitude and direction), sine rule, cosine rule, resolution of forces along " $u$ " and " $v$ " directions that are inclined to each other at an angle $\neq 90$ degree, 2D rectangular resolution of forces into " $x$ " and " $y$ " components.

Problem 1 (Figure 1): Determine the magnitude of the resultant force $F_{R}=F_{1}+F_{2}$ and its direction, measured counterclockwise from the positive $\mathrm{x}$-axis.

Figure 1. Figure for Problem 1

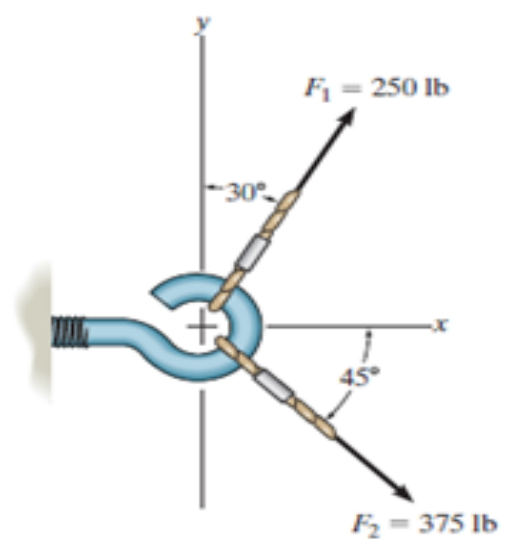

Note: Adapted from Engineering Mechanics: Statics, by R. C. Hibbeler, 2013, Upper Saddle River, New Jersey: Pearson Prentice Hall. Copyright 2013 by R.C. Hibbeler. 
Problem 2 (Figure 2): Resolve the force $F_{2}$ into components acting along the $\mathrm{u}$ and $\mathrm{v}$ axes and determine the magnitudes of the components.

Figure 2. Figure for Problem 2

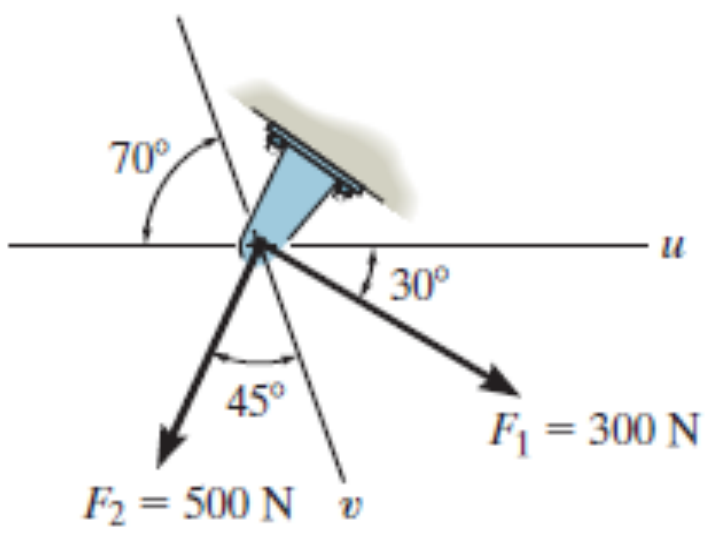

Note: Adapted from Engineering Mechanics: Statics, by R. C. Hibbeler, 2013, Upper Saddle River, New Jersey: Pearson Prentice Hall. Copyright 2013 by R.C. Hibbeler.

Problem 3 (Figure 3): Determine the magnitude and direction of the resultant $F_{R}=F_{1}+F_{2}+F_{3}$ of the three forces by first finding the resultant $F^{\prime}=F_{1}+F_{2}$ and then forming $F_{R}=F^{\prime}+F_{3}$

Figure 3. Figure for Problem 3

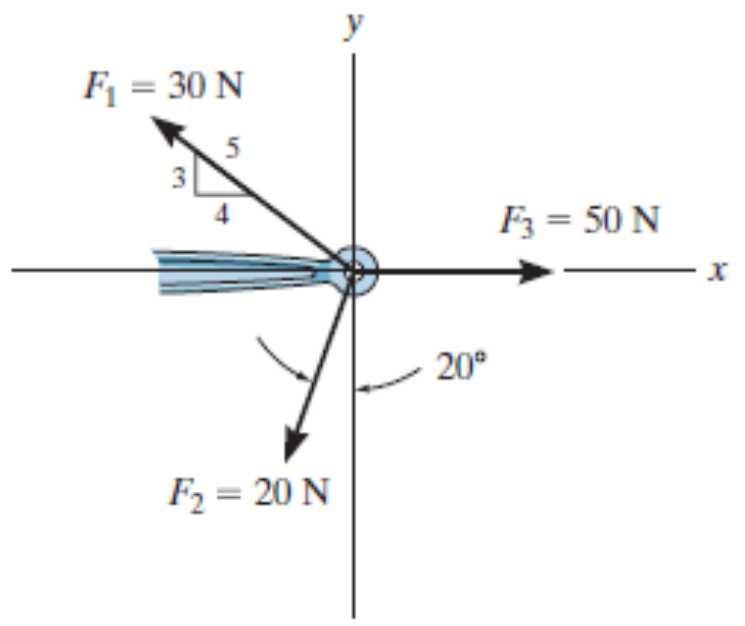

Note: Adapted from Engineering Mechanics: Statics, by R. C. Hibbeler, 2013, Upper Saddle River, New Jersey: Pearson Prentice Hall. Copyright 2013 by R.C. Hibbeler.

Topics of discussion during the week: 3D Force vectors, 3D force resultants (magnitude and direction), sine representation of forces in $\mathrm{i}, \mathrm{j}, \mathrm{k}$ components, coordinate direction angles. 
Problem 4 (Figure 4): Determine the magnitude and direction of the resultant force acting on the assembly.

Figure 4. Figure for Problem 4

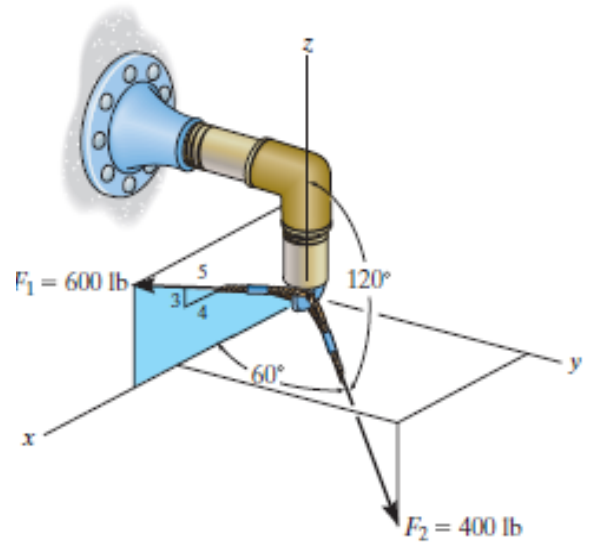

Note: Adapted from Engineering Mechanics: Statics, by R. C. Hibbeler, 2013, Upper Saddle River, New Jersey: Pearson Prentice Hall. Copyright 2013 by R.C. Hibbeler.

Topics of discussion during the week: Shear and moment functions in a beam, shear and moment diagrams for a beam.

Problem 5 (Figure 5): Obtain the shear and moment functions for the beam shown.

Figure 5. Figure for Problem 5

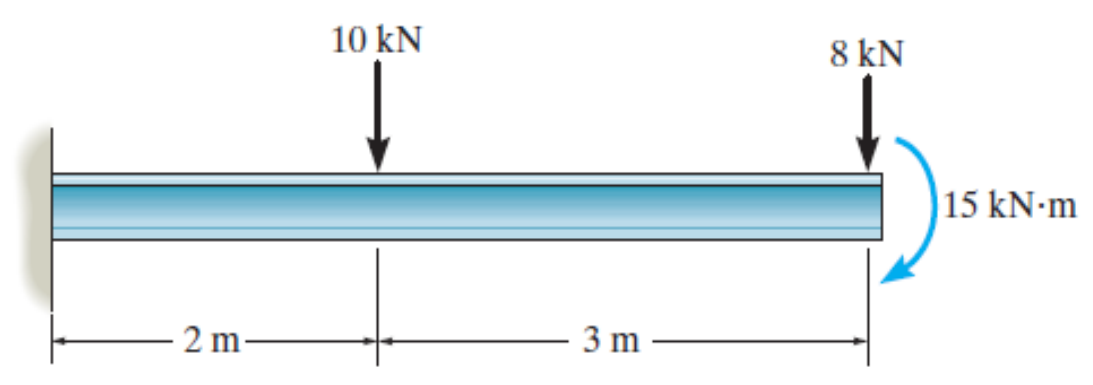

Note: Adapted from Engineering Mechanics: Statics, by R. C.

Hibbeler, 2013, Upper Saddle River, New Jersey: Pearson Prentice

Hall. Copyright 2013 by R.C. Hibbeler. 
Problem 6 (Figure 6): Draw the shear and moment diagrams for the beam shown.

Figure 6. Figure for Problem 6

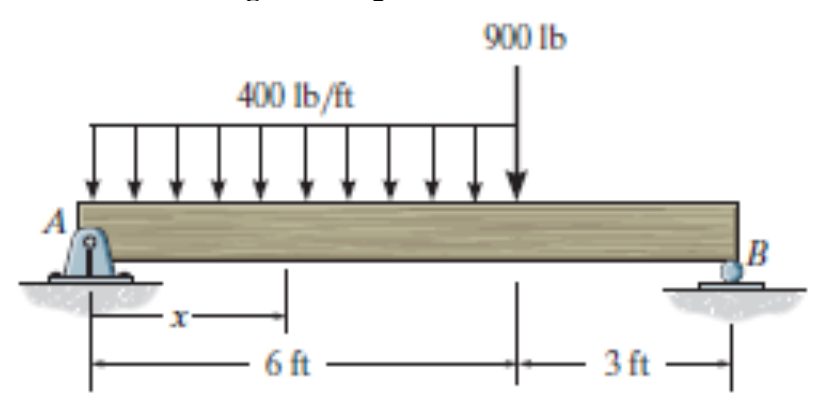

Note: Adapted from Engineering Mechanics: Statics, by R. C. Hibbeler, 2013, Upper Saddle River, New Jersey: Pearson Prentice Hall. Copyright 2013 by R.C. Hibbeler.

Course: Mechanics of Materials.

Topics of discussion during the week: Flexure Formula.

Problem 7 (Figure 7): If the beam is subjected to an internal moment of $\mathrm{M}=30 \mathrm{kN}-\mathrm{m}$, determine the maximum bending stress in the beam. The beam is made from A992 steel. Sketch the bending stress distribution on the crosssection.

Figure 7. Figure for Problem 7

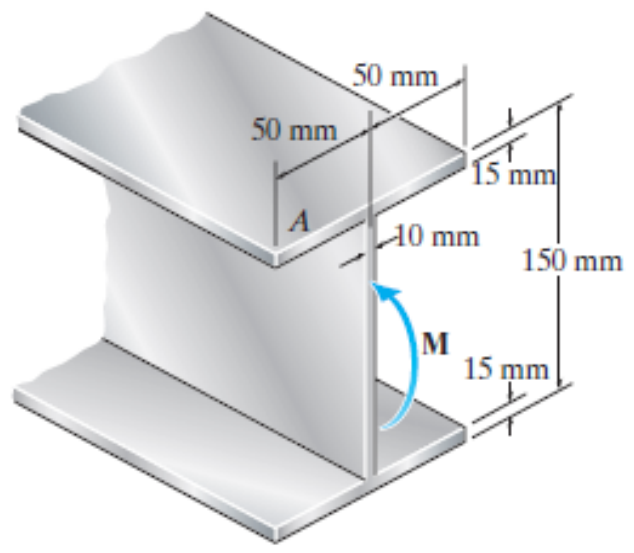

Note: Adapted from Mechanics of Materials, by R. C. Hibbeler, 2013, Upper Saddle River, New Jersey: Pearson Prentice Hall. Copyright 2013 by R.C. Hibbeler. 
Problem 8 (Figure 8): The T-beam is subjected to a bending moment of $M=150$ kip-in directed as shown. Determine the maximum bending stress in the beam and the orientation of the neutral axis. The location of the centroid must be determined.

Figure 8. Figure for Problem 8

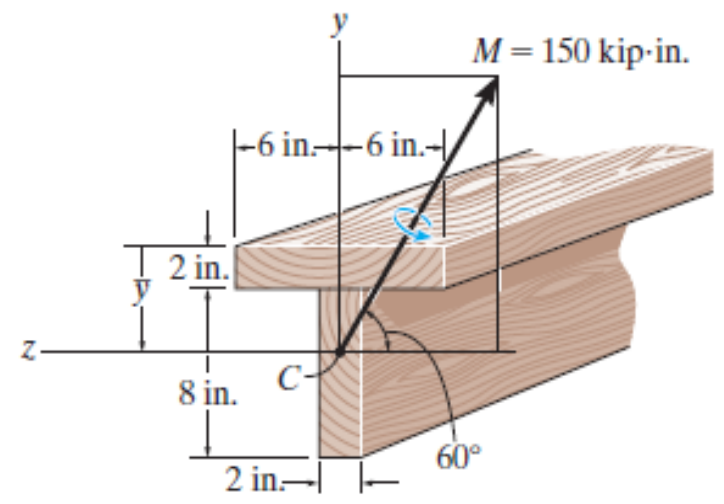

Note: Adapted from Mechanics of Materials, by R. C. Hibbeler, 2013, Upper Saddle River, New Jersey: Pearson Prentice Hall. Copyright 2013 by R.C. Hibbeler.

\section{Sample Quiz Problems - Computer Information Technology}

This section contains samples problems that were included in quizzes conducted in computer programming courses. The problems attempted to cover the basic concepts discussed during the week of the quiz. The quiz was administered during the course's weekly lab component. The quiz consisted of one programming problem to be implemented and debugged fully using the development environment for the computer language. The quiz problem was displayed to the class via the lab projector and was not hardcopy. The goal of the quiz was to test whether the students could apply the programming concepts presented during the week via a fully implemented and debugged program.

Course: Introduction to $\mathrm{C}++$ Programming.

Topics of discussion during the week: Looping \& File I/O.

\section{Problem 9:}

1. Open a file into which you will write some numeric data.

2. Create a "for" loop which loops ten times and thereby writes ten numbers into the output file. The numbers written to the output file should be calculated by adding five to the iteration count in the "for" loop. Make sure to add a newline after each number written out.

3. Close the file when finished.

Topics of discussion during the week: Functions.

\section{Problem:}

1. Write a program which calculates your pay for the week and displays the gross pay to the screen.

2. Write a function for the title of the application.

3. Write a function that gets the number of hours worked for the week.

4. Write a function that calculates the gross pay and returns the gross pay to the main calling function.

5. Call all functions from the main program. 
6. Display the total gross pay to two decimal places to the console window. Call the display function from the main program.

Course: Introduction to Object Oriented Programming

Topics of discussion during the week: Arrays.

\section{Problem:}

1. Create an integer array that is of size 10 .

2. Initialize the array with numbers.

3. Search for the number 10 in the array and output a message to the screen if it is found or not found.

4. Print out the contents of the array.

5. Print out the average for the array.

Topics of discussion during the week: Classes.

Problem:

1. Define a Teacher class that has data items for TeacherID, Lastname, Firstname, and school system.

2. Write $\mathrm{C} \#$ get and set methods for each of the data items in the Teacher class.

3. Write a display method within the Teacher class to display the object content.

4. In the main program, instantiate a teacher object, populate it with values.

5. Call the display method from the object to display the content.

Course: Operating Systems Tech.

Topics of discussion during the week: Introduction to Windows Server Chap 4-5 (multiple choice). Below are 5 questions from a set of 25.

\section{Problem:}

Question: True/False

A disk that is initialized via the Disk Management MMC is initialized as an MBR disk by default.

Question: True/False

A parity space storage layout is similar to a RAID 1 volume, in that a parity bit is written to the spare drive.

Question: True/False

Thin provisioning allocates all configured space immediately, ensuring that the configured space is available for the specified virtual disk.

Question: True/False

NTFS permissions on a file only apply when a file or folder is accessed locally.

Question: True/False

By default, administrators are subject to quota limits. 


\section{Topic of the week: MCSA}

\section{Problem:}

Question: True/False

The recommended minimum number of Active Directory domain controllers in a domain environment is two.

Question 2: True/False

Information within an OU can be hidden using permissions, and administration of an OU can be delegated to a non-administrative account.

Question 3: True/False

An explicit "allow" permission will override an inherited "deny" permission.

Question 4: True/False

Permission inheritance can be configured such that permissions are only inherited by specific types of child object types.

Question 5: True/False

The Administrator account should not be re-named, but should at least used a secure password.

\section{MEASURES}

There were 278 students that took part in the study. The students in elementary and advanced structural analysis, reinforced concrete design, steel design, structural dynamics 1 and 2 were all previously in statics and mechanics of materials. Hence, they were not surveyed a second time to prevent repetition. Out of these, 219 students from both domains provided feedback about the quiz technique via responses to an anonymous hard-copy survey that was distributed to the entire group after the courses were completed. These surveys were both distributed and collected by another professor, who did not teach the course in question. Tables 2 and 3 present the participant responses to each question in the survey for the two different domains investigated in this paper (namely Engineering and Information Technology). The tables quantify the survey results by displaying both the absolute number of students that provided a positive, negative or neutral response to each question in the survey, as well as the percentage of the total number of participating students that responded in each of the ways above. Additionally, a grade analysis was performed that compared student final grades in the same courses before the quiz technique was implemented to grades after the technique was implemented. 
Table 2. Survey Results for Engineering (Total Number of Respondents $\mathrm{N}=159$ )

\begin{tabular}{|c|c|c|c|c|c|c|}
\hline$Q^{1}$ & positive $^{2}$ & negative $^{3}$ & neutral $^{4}$ & $\%(+)^{5}$ & $\%(-)^{6}$ & $\%$ (neutral) $^{7}$ \\
\hline 1 & 141 & 16 & 2 & 88.7 & 10.1 & 1.3 \\
\hline 2 & 135 & 21 & 3 & 84.9 & 13.2 & 1.9 \\
\hline 3 & 143 & 14 & 2 & 89.9 & 8.8 & 1.3 \\
\hline 4 & 142 & 13 & 4 & 89.3 & 8.2 & 2.5 \\
\hline 5 & 146 & 11 & 2 & 91.8 & 6.9 & 1.3 \\
\hline 6 & 141 & 17 & 1 & 88.7 & 10.7 & 0.6 \\
\hline 7 & 145 & 13 & 1 & 91.2 & 8.2 & 0.6 \\
\hline 8 & 139 & 17 & 3 & 87.4 & 10.7 & 1.9 \\
\hline 9 & 75 & 81 & 3 & 47.2 & 50.9 & 1.9 \\
\hline 10 & 52 & 93 & 14 & 32.7 & 58.5 & 8.8 \\
\hline 11 & 51 & 105 & 3 & 32.1 & 66.0 & 1.9 \\
\hline 12 & 130 & 21 & 8 & 81.8 & 13.2 & 5.0 \\
\hline 13 & 138 & 13 & 8 & 86.8 & 8.2 & 5.0 \\
\hline 14 & 121 & 32 & 6 & 76.1 & 20.1 & 3.8 \\
\hline $\mathrm{Avg}^{8}$ & 122.0 & 32.5 & 4.5 & 76.7 & 20.4 & 2.9 \\
\hline
\end{tabular}

1: Q: Question from survey (see Appendix A)

2: positive: Total number of students that provided positive feedback

3: negative: Total number of students that provided negative feedback

4: neutral: Total number of students that provided neutral feedback

5: \% (+): Positive feedback expressed as a percentage of the total number of students that responded to the survey

6: \% (-): Negative feedback expressed as a percentage of the total number of students that responded to the survey

7: \% (Neutral): Neutral feedback expressed as a percentage of the total number of students that responded to the survey

8: Avg: Average of all 15 questions

Table 3. Survey Results for Computer Information Technology (Total Number of Respondents $N=60$ )

\begin{tabular}{|c|c|c|c|c|c|c|}
\hline $\mathbf{Q}$ & Positive & negative & neutral & $\%(+)$ & $\%(-)$ & $\%$ (neutral) \\
\hline 1 & 56 & 3 & 1 & 93.3 & 5.0 & 1.7 \\
\hline 2 & 49 & 6 & 5 & 81.7 & 10.0 & 8.3 \\
\hline 3 & 50 & 5 & 5 & 83.3 & 8.3 & 8.3 \\
\hline 4 & 43 & 6 & 11 & 71.7 & 10.0 & 18.3 \\
\hline 5 & 50 & 4 & 6 & 83.3 & 6.7 & 10.0 \\
\hline 6 & 54 & 6 & 0 & 90.0 & 10.0 & 0.0 \\
\hline 7 & 50 & 3 & 7 & 83.3 & 5.0 & 11.7 \\
\hline 8 & 50 & 7 & 3 & 83.3 & 11.7 & 5.0 \\
\hline 9 & 16 & 38 & 6 & 26.7 & 63.3 & 10.0 \\
\hline 10 & 10 & 34 & 16 & 16.7 & 56.7 & 26.7 \\
\hline 11 & 22 & 30 & 8 & 36.7 & 50.0 & 13.3 \\
\hline 12 & 48 & 7 & 5 & 80.0 & 11.7 & 8.3 \\
\hline 13 & 53 & 3 & 4 & 88.3 & 5.0 & 6.7 \\
\hline 14 & 45 & 7 & 8 & 75.0 & 11.7 & 13.3 \\
\hline Avg $^{8}$ & 43.0 & 10.9 & 6.1 & 71.7 & 18.2 & 10.1 \\
\hline
\end{tabular}

\section{SURVEY ANALYSIS}

The objective of this section is to provide evidence that validates points 1,2 , and 3 in the "Purpose of the Study" section. The survey feedback showed the efficacy of the "in-class, group-based quiz" approach of continuous student assessment from the student's perspective. For the Engineering quizzes, over $75 \%$ of the total students surveyed responded favorably to 11 of the 14 questions (see column 5 in Table 2). Thus, a majority of the total students responded positively to about $79 \%$ of the questions. Also, not all the responses that were "not positive" were necessarily negative; they were a combination of negative and neutral responses.

Referring to the data in Table 3 for the computer information technology quizzes, it can be seen that over $75 \%$ of the total students surveyed responded favorably to 10 of the 14 questions (see column 5 in Table 3 ). Thus, a majority of the total students responded positively to about $71 \%$ of the questions. 
The responses to the questions relevant to the main purposes of incorporating the quizzes are discussed first in the survey analysis. The main goal of this paper is to present a technique that can be used to continuously evaluate student performance while minimizing plagiarism and also create a more interactive classroom environment. Based upon the discussion above, it can be concluded that most students responded positively to the in-class quiz approach for continuous student evaluation.

In particular, $87.4 \%$ (see column 5 corresponding to question 8 in Table 2) of the participating students in engineering and $83.3 \%$ of the participating students in computer information technology (see column 5 corresponding to question 8 in Table 3) responded positively to question 8 . Therefore, the fundamental purpose of this approach was satisfied.

Question 8: "Were the quizzes successful in providing you with a continuous evaluation of your progress, thereby helping you to understand which concepts you needed to work on at the end of every week $(Y / N)$ ?"

Additional support of the quizzes performing their goal of providing students with a continuous evaluation of their learning can be seen in their responses to question 6 . In particular, 88.7\% (see column 5 corresponding to question 6 in Table 2) of engineering students and $90 \%$ (see column 5 corresponding to question 6 in Table 3) of computer information technology students responded positively to the question below:

Question 6: Did the quizzes assist in your ability to absorb and apply fresh material learned without having structured segments of time to learn the material independently $(Y / N)$ ?

Finally, responses to Question 14 showed that the quizzes helped students take responsibility for their learning and avoid procrastination by acting upon the continuous evaluation of their performance that they received on a weekly basis via the quizzes. In particular, $76.1 \%$ for engineering (see column 5 corresponding to question 14 in Table 2), and $75 \%$ (see column 5 corresponding to question 14 in Table 3) for computer information technology responded positively. These responses provided additional evidence that the quizzes achieved their main goal of continuously evaluating students' learning progress and forcing them to work regularly and consistently (see question 14 below).

Question 14: Did you feel that the quizzes forced you not to put off learning the weekly material (i.e. did not allow you to leave unfinished work to a later date), thereby encouraging personal responsibility and discipline $(Y / N)$ ?

However, the response to question 10 of the survey is worthy of attention:

Question 10: "Did you find there was a mismatch (an unequal contribution between members) in the amount of effort contributed by each group member to solving the quiz problems? In other words, did you find the group relied on one member to get the job done? $(Y / N)$ ?"

The tabulated survey results show that only $32.7 \%$ of the total number of engineering students surveyed (see column 5 corresponding to question 10 in Table 2) responded positively to this question. The majority of students $(58.5 \%$, see column 6 corresponding to question 10 in Table 2) felt that the different team members contributed equally in the solution process, and the remainder felt neutral toward this issue. However, a third of the students felt that there was an unequal contribution. This situation was anticipated before the pilot study was begun. Even though $32.7 \%$ of the students felt that there was an unequal contribution between group members toward solving the quiz problems, $89.9 \%$ (see column 5 corresponding to question 3 in Table 2) of the engineering participants responded positively to question 3 of the survey:

Question 3: "Did working in peer groups help you understand the material better $(Y / N)$ ?

Was it due to either of these reasons?

a) It might have been easier for you to relate to a peer instead of trying to relate to the instructor.

b) It can be less intimidating to interact with a peer instead of feeling pressured to ask the instructor seemingly small questions.

c) Explaining material to your peer might have improved your understanding of the subject matter." 
Hence, most students felt that working in peer groups helped them understand the subject material better due to the combination of the factors above. Specifically, it may be explained that interacting with a peer can be easier than interacting with an authority figure. Also, working on solving a problem within a team of peers can improve the understanding of the subject material for both the weaker and stronger participants within the group. Both the questioner as well as the person being questioned may serve to benefit from this interaction because the questioner's understanding may improve due to the explanation provided by the person questioned. Additionally, the questioned student's understanding may improve by engaging in the act of teaching the fundamental concepts to the questioner.

In this context, in response to the same question 10 (see column 5 corresponding to question 10 in Table 3), it was seen that only $16.7 \%$ of the students felt that there was an unequal participation within the groups in the computer information technology quizzes. Additionally, 83.3\% (see column 5 corresponding to question 3 in Table 3 ) of those surveyed felt that the group-based approach to solving quiz problems assisted them in their learning process for the same reasons as those discussed in the previous paragraph.

Additionally, in engineering, $89.3 \%$ (see column 5 corresponding to question 4 in Table 2) and in computer information technology $71.1 \%$ (see column 5 corresponding to question 4 in Table 3 ) of the participants responded favorably to question 4 of the survey.

Question 4: "Did working in groups help you establish a sense of camaraderie with your group $(Y / N)$ ?"

Most of the student participants felt that the approach assisted them with working in teams, which is very important in the professional world. Even though this skill is not directly linked to assessing the continuous progress of students, it is a fringe benefit of the quiz approach and makes the classroom more interactive. Collaboration is an important part of this quiz-based approach, as opposed to working on quizzes in isolation.

Furthermore, responses to question 12 showed that one of the main purposes of incorporating these quizzes was fulfilled. Students felt that the quizzes made the classroom more interactive than traditional homework assignments.. Additionally, it created an environment in which students were provided with more personal attention. In particular, $81.8 \%$ (see column 5 corresponding to question 12 in Table 2) of the engineering students and $80 \%$ (see column 5 corresponding to question 12 in Table 3) of the computer information technology students positively supported the statement below:

Question 12: Did you find that being graded via this weekly in-class quiz technique was a more interactive and personalized approach to evaluating your weekly understanding of knowledge, as opposed to the traditional weekly homework assignment approach in which you solve homework problems independently $(Y / N)$ ?

Lectures can occasionally become monotonous and students sometimes find it hard to focus their attention for extended periods of time. Creating a more interactive environment may help to maintain student focus, motivation, and energy in the classroom. Additionally, it may help create a sense of community among students. As described by Robinson \& Collofello (2012), Citty \& Bennett (2012), Rawn \& Lindner (2016), Kline, Aller \& Tsang (2011), Neubert, Worley \& Kaabouch (2011), and Desai \& Stefanek (2017), developing a sense of community in engineering and technology classrooms has been recommended by researchers as a means to increasing retention in STEM programs. In this context, $86.8 \%$ (see column 5 corresponding to question 13 in Table 2) of the engineering students and $88.3 \%$ (see column 5 corresponding to question 13 in Table 3 ) of the computer information technology students felt that the quizzes energized them and made the classroom livelier.

Question 13: Do you feel that these quizzes were an energizing diversion from continuously and passively listening to a lecture $(Y / N)$ ?

Also, in response to question 11 in the survey, it can be clearly seen that most of the students preferred working in groups as compared to working individually.

Question 11: Would you have rather worked independently instead of within a group $(Y / N)$ ? 
In particular, $32.1 \%$ (see column 5 corresponding to question 11 in Table 2) of the students in engineering and $36.7 \%$ (see column 5 corresponding to question 11 in Table 3) of those in computer information technology said that they would have rather worked alone. These could have been the higher performing students. However, responses to questions 3 and 4 demonstrate that the students valued teamwork and collaboration which are essential ingredients of working as professionals.

A unique feature of the described approach involves free and open interaction with the instructor to obtain guidance, if necessary. Since the quizzes are completed by students shortly after learning a new concept, the quizzes test a student's ability to apply the new material that they haven't yet had time to study. Under such circumstances, it is reasonable to expect the need for students to ask for small hints or guidance from the instructor. This option to ask for the instructor's assistance was received very positively by the participants. This is demonstrated by the fact that 91.2\% (see column 5 corresponding to question 7 in Table 2) of engineering students and $83.3 \%$ of computer information technology (see column 5 corresponding to question 7 in Table 3) students felt that the quizzes helped them build rapport with their instructor. Question 7 is presented below.

Question 7: "Did you feel that having the freedom to ask the instructor for guidance within this process contributed toward building rapport, trust, and interaction between you and the instructor $(Y / N)$ ?"

The main points 1, 2, and 3 in the section titled "Purpose of the Study" have been supported by the above analysis for both the engineering and computer information technology quizzes. Some additional benefits of incorporating the quizzes are presented below.

The quizzes succeeded in motivating students to attend class regularly and pay attention in class. This can be concluded from the responses to questions 1 and 2. In particular, $88.7 \%$ (see column 5 corresponding to question 1 in Table 2) of the students in engineering and $93.3 \%$ (see column 5 corresponding to question 1 in Table 3 ) of the students in computer information technology responded positively to question 1 .

Question 1: Did the prospect of taking an in-class quiz that contributed to your final grade motivate you to try to attend class more regularly $(Y / N)$ ?

Similarly, $84.9 \%$ (see column 5 corresponding to question 2 in Table 2) of the students in engineering and $81.7 \%$ (see column 5 corresponding to question 2 in Table 3 ) of the students in computer information technology responded positively to question 2 in the survey.

Question 2: Did the prospect of taking a quiz at the end of class that contributed to your final grade motivate you to try to pay more attention to the lecture $(Y / N)$ ?

The quizzes provided students with a balance between performing in real-time and having the comfort of relying on a support group. This can be seen from the responses to Question 5. The responses showed that $91.8 \%$ (see column 5 corresponding to question 5 in Table 2) of the engineering students and $83.3 \%$ (see column 5 corresponding to question 5 in Table 3 ) of the computer information technology students felt that this was true.

Question 5: Did you get the impression that the in-class quizzes provided a balance between performing during $a$ quiz while having the flexibility of support within a group $(Y / N)$ ?

The objective of the quiz-based approach was to obtain a continuous evaluation of students in a manner that eliminated the chance that they might plagiarize material, while also creating a relatively informal and relaxed environment in which learning can take place. The traditional homework approach offers a low-stress testing environment but has the drawback of possible plagiarism.

The authors were concerned that students' grades would suffer due to them being absent from class and thereby missing quizzes. However, based upon responses to question 9 below, the majority of students in both engineering and computer information technology stated that they did not face this issue. Responses to question 1 also demonstrated that the majority of students stated that the quizzes motivated them to attend class more regularly. 
Question 9: Since these quizzes are done in class, if you missed a quiz or quizzes for a sincere reason, you might have lost some points which in turn adversely affected your grade. Did you experience this problem $(Y / N)$ ?

\section{GRADE ANALYSIS}

While the discussion in the "Survey Analysis" section above validated points 1, 2, and 3 in the "Purpose of the Study" section, the purpose of this section is to provide evidence that supports point 4 of that section.

The percentage scores that each student secured in Statics (in years 2013, 2015, and 2016), and mechanics of materials (in 2013) are presented in Tables 3, 4, 5, and 6 in Appendix B. The scores for Statics (in 2014) are unavailable and hence were not added to this analysis. The civil engineering department was created at the University in the fall of 2013. Since it is a new department, the number of students in the core civil engineering courses (elementary and advanced structural analysis, reinforced concrete design, steel design, and structural dynamics 1 and 2) was small. Due to this small number of students, these courses had only one section. Additionally, these courses were not offered before the addition of the civil engineering department. Hence, even though the proposed technique was implemented in these courses, it was not possible to compare the percentage scores with and without the proposed technique implemented. However, these students did complete Statics and Mechanics of Materials, and their survey feedback was analyzed.

Tables 3, 4, 5, and 6 show the final grade percentage score for each student, and show the average score for the entire class. The scores are compared between two different sections of each course (the sections being conducted in parallel in the same year and same semester, one incorporating the technique proposed in this study and the other not incorporating the technique). The course section in which the technique was not incorporated into the course was taught by another faculty member at the same university who did not use the quiz-based technique. The material taught was nearly identical, and the level of difficulty of exams was similar. Point 4 in "Purpose of the Study" stated that it was desired to demonstrate that this technique, at a minimum, does not decrease student performance in class. Student performance in class is measured as the overall final grade percentage score in the course at the semester end. Point 4 in "Purpose of the Study" also stated that it was desired to show that this technique may improve student performance in class, and be universally implemented independently of the instructor teaching the course.

The average total overall final grade percentage score in statics (2013) was $82.1 \%$ with the proposed technique incorporated, versus $80.82 \%$ without the quiz technique. Thus, there was a $1.28 \%$ improvement in the average percentage of the class on incorporating the proposed technique. Even though this is a small improvement, the average class performance did not decrease, demonstrating that the quizzes did not have a negative impact on student performance measured by the final grade percentage score. As mentioned in the "Purpose of the Study" section, the authors were concerned that the incorporation of quizzes that did not provide students with preparation time could potentially adversely affect their overall scores in the course. Similarly, the average class percentage in statics (2015) increased by $5.65 \%$ from $77.11 \%$ to $82.76 \%$ on incorporating the proposed technique. Finally, there was an improvement in the average percentage scores in mechanics of materials (2013): the scores improved by $11.46 \%$ in the section that incorporated the proposed technique.

In the fall of 2016, the in-class, group-based quiz technique was incorporated into all the sections of the Statics courses that were offered. There were three sections offered, two of which were conducted by one instructor and the remaining section by a different instructor. Additionally, the sections were taught on two different campuses of the same university. Before the fall of 2016, the two different campuses existed as two separate universities. However, the campuses were unified into one university in the fall of 2016. Post-unification, the class sizes were nearly tripled, and the same course (statics) was offered on two different campuses. It was interesting to note that despite the incorporation of the quiz technique in much larger classes on two different campuses, the overall average class final grade percentage score was still higher than what it was before the incorporation of the quizzes. The class average in the section at one of the campuses was $82.5 \%$, and was $81.1 \%$ and $84.3 \%$ for the two sections taught on the second campus. 
The in-class, group-based quiz technique was also applied to two programming courses in the Computer Information Technology department: Introduction to $\mathrm{C}++$ Programming and Introduction to Object Oriented Programming. Additionally, this quiz technique was also applied to an operating system course in computer information technology, called Operating Systems Technology. The latter course is different in that it involves learning how to install and configure operating systems, while the former courses teach students computer programming. In 2015, there were 33 students enrolled in the $\mathrm{C}++$ programming course where the technique was not used and in 2016 there were 30 students enrolled in the same course where the technique was used. In 2016, there were 19 students enrolled in the introduction to object-oriented programming course where the technique was used. There was no data available for previous years where the technique was not used in the course. Finally, in 2016 there were 22 students enrolled in the Operating Systems Technology course where the technique was used. There was no data available for previous years where the technique was not used in the course. As demonstrated in the "Method" section, the quiz questions in this course were multiple-choice.

The final grade percentage scores for the Introduction to $\mathrm{C}++$ Programming courses are presented in Table 7. The same professor taught all the C++ courses in 2015 and 2016. The content and level of difficulty of the course and its exams were nearly identical. Table 7 shows that the overall final grade percentage score for this course for the year 2015 , where the proposed quiz technique was not incorporated, was $75.8 \%$. The incorporation of the proposed quiz technique resulted in an increase of $1 \%$ in the overall final grade percentage score for this course in 2015. In 2016, the incorporation of the in-class, group-based quiz technique resulted in an average final grade percentage score of 79.6 which was $3.3 \%$ higher than when the technique was not used in the course. Hence, like the engineering courses discussed previously, it can be seen from the above analysis that the incorporation of the proposed in-class, group-based quiz technique into the Introduction to $\mathrm{C}++$ Programming course in the Computer Information Technology department did not result in a decrease in the average class percentage.

The final grade percentage scores for the Introduction to Object Oriented Programming courses, where the quiz technique was not used, were not available. Since this course is a programming course with similar content to the Introduction to $\mathrm{C}++$ Programming course, we used the latter course as an approximate reference for comparison with the former course. Table 8 shows that the average final grade percentage score for the Introduction to Object Oriented Programming course in 2016, where the quiz technique was used, was $83.2 \%$. This was $6.9 \%$ higher than the average final grade percentage score for the Introduction to C++ Programming course in 2015 where the quiz technique was not used. This result additionally supports the goal in point 4 in the "Purpose of the Study" section.

Table 9 shows that the average final grade percentage score for the Operating Systems Tech course in 2016, where the quiz technique was used, was $82.6 \%$. There is no data available for this course where the quiz technique was not implemented. However, the average final grade percentage score was approximately the same as in the programming courses additionally adding support to the objective in point 4 in the "Purpose of the Study" section.

\section{RESULTS}

It can be concluded that:

- The proposed method was successfully implemented (evidenced below by the results in bullet points 2 , 3 , and 4) in both engineering and computer information technology courses, demonstrating its versatility. Hence, objective 1 in the "Purpose of the Study" section was satisfied.

- The proposed method reduced plagiarism. The continuous evaluation of student performance was done in the classroom in the instructor's presence. Interaction with the instructor was permitted instead of the traditional homework-based approach, thereby removing the potential for plagiarizing. Hence, objective 2 in the "Purpose of the Study" section was satisfied.

- Based on student feedback, $91.2 \%$ of the students in engineering and $83.3 \%$ of the students in computer information technology felt that the proposed quiz technique helped them build rapport with the instructor. Additionally, $89.3 \%$ of the students in engineering and $71.1 \%$ of the students in computer information technology felt that the proposed technique helped develop a sense of camaraderie in the classroom. Hence, the proposed technique succeeded in making the learning process an interactive one. Hence, objective 3 in the "purpose of the study" section was satisfied. 
- The incorporation of the proposed technique resulted in improved student performance as demonstrated by the increased average final grade percentage scores. Improvement in scores ranged from approximately $2-11 \%$. Hence, objective 4 in the "Purpose of the Study" section was satisfied, since student performance did not decrease by including real-time quiz performance in their assessment.

\section{CONCLUSIONS}

Traditionally, evaluation of student performance in the classroom included conducting examinations which tested a student's accumulated effort and knowledge over time. Additionally, homework assignments were also used to assess the regular weekly knowledge gained by students. We have observed that some students tend to plagiarize homework assignments, either from each other or from online solution manuals. Internet access has made it possible for students to access solutions to problems online. Before the Internet, the traditional approach of homework assignments served as a reasonable indicator of a student's grasp of classroom material on a weekly basis and was more effective than it is today. To circumvent the problem of potential plagiarism, we have recommended an approach of conducting weekly, interactive, in-class, group-based quizzes which provide the instructor and students with a personalized, real-time assessment of the student's understanding of the subject matter taught in the classroom during a particular week.

Based upon the tabulated survey results and grade analysis in the previous section, some of the advantages and disadvantages of the proposed quiz technique are summarized below.

Advantages of the proposed quiz technique:

1. Eliminates plagiarism.

2. Improves regular class attendance.

3. Improves class participation and focus.

4. Improves understanding of subject matter.

5. Improves teamwork and ability to collaborate on future projects.

6. Improves student learning through peer-to-peer interaction.

7. Provides balanced pressure between performance on a quiz and support within a peer group. In comparison, a homework assignment has relatively little pressure (stress) since it is not done in realtime, and is done within the comfort and familiar environment of one's home.

8. Trains students to absorb and freshly apply material without having to allocate structured segments of time to learn the material independently.

9. Contributes toward building rapport, trust, and interaction between the class and the instructor (since the student can ask the instructor for guidance).

10. Prevents a students' final grade from being disproportionately affected by a single, bad day on a quiz (since quizzes are administered weekly unlike a mid-term or final exam).

11. Provides a continuous evaluation of the student that allows the instructor to make weekly adjustments to his/her teaching style and helps the instructor to emphasize specific topics that are found to be problematic on the quizzes.

12. Provides continuous feedback to the student to help the student focus their study efforts.

13. Reduces the grading load on the instructor by dividing the class into groups.

14. Increases interaction between students and the instructor.

\section{Disadvantages of the proposed quiz technique:}

1. Students may lose some points if they miss quizzes regularly, thereby affecting their grade.

2. Intentionally insincere students may contribute less within a group.

The pros of the proposed approach outnumber the cons. The process was more interactive and helped reduce plagiarism while ensuring that at a minimum, student performance measured as an average overall percentage for 
the class did not decrease despite students being tested in real-time on material without having any allocated preparation time.

\section{AUTHOR BIOGRAPHIES}

Dr. Niranjan Desai received his Ph.D. in civil engineering from the University of Louisville and is currently an assistant professor at Purdue University Northwest. His areas of interest are engineering education, seismic analysis of structures and structural health monitoring.

Dr. George Stefanek received his Ph.D. from the Illinois Institute of Technology and his areas of interest include engineering education and computer information technology and graphics.

\section{REFERENCES}

Arteaga, I. L., \& Vinken, E. (2013). Example of good practice of a learning environment with a classroom response system in a mechanical engineering bachelor course. European Journal of Engineering Education, 38(6), 652-660.

Bälter, O., Enström, E., \& Klingenberg, B. (2013). The effect of short formative diagnostic web quizzes with minimal feedback. Computers \& Education, 60(1), 234-242.

Citty, C. \& Bennett, R. (2012, June). Research and instructional strategies for engineering retention. Paper presented at the ASEE 2012 Annual Conference and Exposition, San Antonio, TX.

Desai, N. \& Stefanek, G. (2016, June). Continuous evaluation of student class performance using group-based, in-class quizzes. Paper presented at the ASEE 123rd Annual Conference and Exposition, New Orleans, LA.

Desai, N. \& Stefanek, G. (2017, March). A literature review of the different approaches that have been implemented to increase retention in engineering programs across the United States. Paper presented at the ASEE Zone 2 Conference, San Juan, Puerto Rico.

Drew, C. (2011). Why science majors change their minds (It's just so darn hard). New York Times, 4.

Evering, L. C., \& Moorman, G. (2012). Rethinking plagiarism in the digital age. Journal of Adolescent \& Adult Literacy, 56(1), 35-44.

Faraji, S. (2012). The enhancement of student's learning in both lower-division and upper-division classes by a quiz-based approach. Chemical Engineering Education, 46(3), 213-217.

Gross, E. R. (2011). Clashing values: Contemporary views about cheating and plagiarism compared to traditional beliefs and practices. Education, 132(2), 435-441.

Hannah, J., James, A., \& Williams, P. (2014). Does computer-aided formative assessment improve learning outcomes? International Journal of Mathematical Education in Science and Technology, 45(2), 269-281.

Kitsantas, A., \& Zimmerman, B. J. (2009). College students' homework and academic achievement: The mediating role of selfregulatory beliefs. Metacognition and Learning, 4(2), 97-110.

Kline, A., Aller, B. \& Tsang, E. (2011, June). Improving student retention in STEM disciplines: a model that has worked. Paper presented at the ASEE 2011 Annual Conference and Exposition, Vancouver, BC.

Neubert, J., Worley, D. \& Kaabouch, N. (2011, June). Using undergraduate mentors to deliver engineering content to calculus for increased persistence in engineering. Paper presented at the ASEE 2011 Annual Conference and Exposition, Vancouver, BC.

Rawn, J. \& Lindner, A. (2016, June). Dual model summer bridge programs: a new consideration for increasing retention rates. Paper presented at the ASEE 123rd Annual Conference and Exposition, New Orleans, LA.

Robinson, C. \& Collofello, J. (2012, June). Utilizing undergraduate teaching assistants in active learning environments. Paper presented at the ASEE 2012 Annual Conference and Exposition, San Antonio, TX.

Shafiq, F., \& Siddiquah, A. (2011). Effect of classroom quizzes on graduate students' achievement. International Journal of Academic Research, 3(5), 76-79.

Shorter, N. A., \& Young, C. Y. (2011). Comparing assessment methods as predictors of student learning in an undergraduate mathematics course. International Journal of Mathematical Education in Science and Technology, 42(8), 1061-1067. 


\section{APPENDIX A}

\section{Survey: In-Class Weekly Quiz Approach Feedback}

1) Did the prospect of taking an in-class quiz that contributed to your final grade motivate you to try to attend class more regularly $(\mathrm{Y} / \mathrm{N})$ ?

2) Did the prospect of taking a quiz at the end of class that contributed to your final grade motivate you to try to pay more attention to the lecture $(\mathrm{Y} / \mathrm{N})$ ?

3) Did working in peer groups help you understand the material better $(\mathrm{Y} / \mathrm{N})$ ?

Was it due to either of these reasons?

a) It might have been easier for you to relate to a peer instead of trying to relate to the instructor.

b) It can be less intimidating to interact with a peer instead of feeling pressured to ask the instructor seemingly small questions.

c) Explaining material to your peer might have improved your own understanding of the subject matter.

4) Did working in groups help you establish a sense of camaraderie with your group ( $\mathrm{Y} / \mathrm{N})$ ?

5) Did you get the impression that the in-class quizzes provided a balance between performing during a quiz while having the flexibility of support within a group $(\mathrm{Y} / \mathrm{N})$ ?

6) Did the quizzes assist in your ability to absorb and apply fresh material learned without having structured segments of time to learn the material independently $(\mathrm{Y} / \mathrm{N})$ ?

7) Did you feel that having the freedom to ask the instructor for guidance within this process contributed toward building rapport, trust and interaction between you and the instructor $(\mathrm{Y} / \mathrm{N})$ ?

8) Were the quizzes successful in providing you with a continuous evaluation of your progress, thereby helping you to understand which concepts you needed to work on at the end of every week (Y/N)?

9) Since these quizzes are done in class, if you missed a quiz or quizzes for a sincere reason, you might have lost some points which in turn adversely affected your grade. Did you experience this problem ( $\mathrm{Y} / \mathrm{N})$ ?

10) Did you find there was a mismatch (an unequal contribution between members) in the amount of effort contributed by each group member to solving the quiz problems? In other words, did you find the group relied on one member to get the job done? ( $/ \mathrm{N})$ ?

11) Would you have rather worked independently instead of within a group $(\mathrm{Y} / \mathrm{N})$ ?

12) Did you find that being graded via this weekly in-class quiz technique was a more interactive and personalized approach to evaluate your weekly understanding of knowledge, as opposed to the traditional weekly homework assignment approach in which you solve homework problems independently $(\mathrm{Y} / \mathrm{N})$ ?

13) Do you feel that these quizzes were an energizing diversion from continuously and passively listening to a lecture $(\mathrm{Y} / \mathrm{N})$ ?

14) Did you feel that the quizzes forced you to not put off learning the weekly material (i.e. did not allow you to leave unfinished work to a later date), thereby encouraging personal responsibility and discipline $(\mathrm{Y} / \mathrm{N})$ ? 


\section{APPENDIX B}

Table 3. Statics 2013

\begin{tabular}{|c|c|c|}
\hline \multirow{3}{*}{ Student } & \multicolumn{2}{|c|}{ Section } \\
\hline & With proposed quiz technique & Without proposed quiz technique \\
\hline & Total Score $(\%)$ & Total Score $(\%)$ \\
\hline 1 & 75.77 & 87.93 \\
\hline 2 & 78.87 & 79.20 \\
\hline 3 & 85.99 & 77.26 \\
\hline 4 & 77.69 & 79.96 \\
\hline 5 & 73.19 & 76.94 \\
\hline 6 & 98.98 & 90.73 \\
\hline 7 & 67.82 & 93.10 \\
\hline 8 & 68.91 & 74.03 \\
\hline 9 & 91.82 & 63.90 \\
\hline 10 & 94.49 & 66.59 \\
\hline 11 & 89.50 & 89.76 \\
\hline 12 & $\mathrm{NA}^{1}$ & 75.11 \\
\hline 13 & NA & 96.12 \\
\hline 14 & NA & 87.93 \\
\hline Average & 82.1 & 80.82 \\
\hline
\end{tabular}

Table 4. Statics 2015

\begin{tabular}{c|c|c}
\hline \multirow{2}{*}{ Student } & \multicolumn{2}{|c}{$\begin{array}{c}\text { Section } \\
\text { With proposed quiz technique } \\
\text { Total Score (\%) }\end{array}$} \\
\hline 1 & 89.17 & $\begin{array}{c}\text { Without proposed quiz technique } \\
\text { Total Score (\%) }\end{array}$ \\
\hline 2 & 82.73 & 60.4 \\
\hline 3 & 92.53 & 82.4 \\
\hline 4 & 86.99 & 80.4 \\
\hline 5 & 74.53 & 91.1 \\
\hline 6 & 68.65 & 85 \\
\hline 7 & 79.89 & 66.8 \\
\hline 8 & 79.67 & 78.3 \\
\hline 10 & 75.17 & 76 \\
\hline 11 & 90.06 & 69.5 \\
\hline 12 & 88.92 & 73.8 \\
\hline 13 & 72.95 & 82.7 \\
\hline 15 & 90.23 & 81.9 \\
\hline 16 & 81.48 & 88.5 \\
\hline 17 & 95.14 & 74.4 \\
\hline 18 & 72.99 & 76.5 \\
\hline Average & 90.01 & 66.1 \\
\hline
\end{tabular}


Table 5. Statics 2016

\begin{tabular}{|c|c|c|c|}
\hline Student & Fall 2016 (Section 1) & Fall 2016 (Section 2) & Fall 2016 (Section 3) \\
\hline 1 & 98 & 52.8 & 90.90 \\
\hline 2 & 99 & 63.5 & 97.45 \\
\hline 3 & 96 & 83.1 & 92.96 \\
\hline 4 & 95 & 67.2 & 90.26 \\
\hline 5 & 78.5 & 73.0 & 75.83 \\
\hline 6 & 98 & 59.4 & 79.10 \\
\hline 7 & 91.8 & 89.2 & 92.85 \\
\hline 8 & 81.25 & 63.0 & 89.46 \\
\hline 9 & 97 & 88.1 & 89.30 \\
\hline 10 & 67 & 86.0 & 77.52 \\
\hline 11 & 90 & 94.5 & 68.00 \\
\hline 12 & 94 & 92.0 & 76.53 \\
\hline 13 & 56 & 61.0 & 88.84 \\
\hline 14 & 75.7 & 71.5 & 72.37 \\
\hline 15 & 75 & 69.8 & 66.18 \\
\hline 16 & 93 & 93.3 & 56.93 \\
\hline 17 & 80 & 92.0 & 99.01 \\
\hline 18 & 100 & 68.9 & 80.53 \\
\hline 19 & 87.8 & 63.5 & 56.91 \\
\hline 20 & 70 & 82.4 & 83.87 \\
\hline 21 & 68.2 & 85.7 & 82.37 \\
\hline 22 & 65.3 & 59.0 & 92.43 \\
\hline 23 & 94 & 96.5 & 93.82 \\
\hline 24 & 83.2 & 92.4 & 87.10 \\
\hline 25 & 82.7 & 75.3 & 78.16 \\
\hline 26 & 57.4 & 98.0 & 82.06 \\
\hline 27 & 57.1 & 98.0 & 53.78 \\
\hline 28 & 61.8 & 90.7 & 85.06 \\
\hline 29 & 57.8 & 91.6 & 92.63 \\
\hline 30 & 73.5 & 99.0 & 100.52 \\
\hline 31 & 83 & 97.0 & 73.37 \\
\hline 32 & 76.6 & 99.0 & 91.39 \\
\hline 33 & 69.8 & 99.0 & 97.52 \\
\hline 34 & 98 & 98.0 & 95.25 \\
\hline 35 & 99 & 84.7 & 94.55 \\
\hline 36 & 96 & 87.6 & 61.36 \\
\hline 37 & 95 & 66.1 & 64.31 \\
\hline 38 & 78.5 & 100.0 & 100.22 \\
\hline 39 & 98 & 50.2 & 90.98 \\
\hline 40 & NA & 61.6 & 95.22 \\
\hline 41 & NA & NA & 92.06 \\
\hline 42 & NA & NA & 77.44 \\
\hline 43 & NA & NA & 97.84 \\
\hline 44 & NA & NA & 82.14 \\
\hline 45 & NA & NA & 81.29 \\
\hline 46 & NA & NA & 95.39 \\
\hline 47 & NA & NA & 99.53 \\
\hline Average & 82.5 & 81.1 & 84.3 \\
\hline
\end{tabular}


Table 6. Mechanics of Materials 2013

\begin{tabular}{|c|c|c|}
\hline \multirow{3}{*}{ Student } & \multicolumn{2}{|c|}{ Section } \\
\hline & with proposed quiz technique & without proposed quiz technique \\
\hline & Total Score (\%) & Total Score $(\%)$ \\
\hline 1 & 89.95 & 80 \\
\hline 2 & 98.34 & 85 \\
\hline 3 & 93.47 & 80 \\
\hline 4 & 80.31 & 60 \\
\hline 5 & 85.94 & 64 \\
\hline 6 & 76.48 & 82 \\
\hline 7 & 95.19 & 79 \\
\hline 8 & 93.51 & 95 \\
\hline 9 & 100.26 & 78 \\
\hline 10 & 83.92 & 76 \\
\hline 11 & 100.70 & 75 \\
\hline 12 & 83.12 & 78 \\
\hline 13 & 101.93 & 78 \\
\hline 14 & 96.06 & 76 \\
\hline 15 & 91.49 & 78 \\
\hline 16 & 76.51 & 80 \\
\hline 17 & 89.85 & 65 \\
\hline 18 & 85.69 & 81 \\
\hline 19 & 62.32 & NA \\
\hline Average & 88.68 & 77.22 \\
\hline
\end{tabular}


Table 7. Introduction to Programming in $\mathrm{C}++$

\begin{tabular}{|c|c|c|c|}
\hline \multirow{3}{*}{ Student } & \multicolumn{3}{|c|}{ Section } \\
\hline & $\begin{array}{l}\text { with proposed quiz technique } \\
\text { (2016) }\end{array}$ & $\begin{array}{l}\text { without proposed quiz technique } \\
\text { (Spring, 2015) }\end{array}$ & $\begin{array}{l}\text { without proposed quiz technique } \\
\text { (Fall, 2015) }\end{array}$ \\
\hline & Total Score (\%) & Total Score (\%) & Total Score (\%) \\
\hline 1 & 86.5 & 61.2 & 81.4 \\
\hline 2 & 73.9 & 81.3 & 83 \\
\hline 3 & 79.4 & 65 & 84.5 \\
\hline 4 & 47.5 & 53 & 82 \\
\hline 5 & 32.9 & 63.7 & 94.4 \\
\hline 6 & 87.4 & 75.4 & 78.7 \\
\hline 7 & 97.1 & 77.7 & 63.9 \\
\hline 8 & 96.3 & 90.4 & 68.6 \\
\hline 9 & 75 & 85.8 & 100 \\
\hline 10 & 76.7 & 91 & 94.2 \\
\hline 11 & 79.6 & 87.2 & 52.3 \\
\hline 12 & 77.7 & 89.7 & 78.9 \\
\hline 13 & 84.8 & 63.8 & 66.8 \\
\hline 14 & 84.6 & 61.7 & 81.2 \\
\hline 15 & 77 & NA & 83 \\
\hline 16 & 65.3 & NA & 48.3 \\
\hline 17 & 85.7 & No student & 97.6 \\
\hline 18 & 93.8 & No student & 69.6 \\
\hline 19 & 64.3 & No student & 50.6 \\
\hline 20 & 69.8 & No Student & No student \\
\hline 21 & 87.9 & No student & No student \\
\hline 22 & 78.5 & No student & No student \\
\hline 23 & 85.7 & No student & No Student \\
\hline 24 & 92.9 & No Student & No student \\
\hline 25 & 83.2 & No student & No student \\
\hline 26 & 83.4 & No student & No student \\
\hline 27 & 85.8 & No student & No Student \\
\hline 28 & 99.1 & No Student & No student \\
\hline 29 & 64.1 & No student & No student \\
\hline 30 & 100 & No student & No student \\
\hline 31 & No student & No student & No student \\
\hline 32 & No student & No Student & No Student \\
\hline 33 & No Student & No student & No student \\
\hline 34 & No student & No student & No student \\
\hline Average & 79.6 & 75.8 & 76.8 \\
\hline
\end{tabular}


Table 8. Introduction to Object-Oriented Programming

\begin{tabular}{c|c}
\hline Student & Section (Spring 2016) \\
\hline 1 & 98.4 \\
\hline 2 & 89.6 \\
\hline 3 & 92.3 \\
\hline 4 & 71 \\
\hline 5 & 97 \\
\hline 6 & 92.5 \\
\hline 7 & 76.5 \\
\hline 8 & 94 \\
\hline 9 & 98 \\
\hline 10 & 65.2 \\
\hline 11 & 49.8 \\
\hline 12 & 93.3 \\
\hline 13 & 86.7 \\
\hline 14 & 80 \\
\hline 15 & 77.5 \\
\hline 16 & 71.6 \\
\hline 17 & 77.3 \\
\hline 18 & 90.8 \\
\hline 19 & 80 \\
\hline 20 & NA \\
\hline Average & 83.2 \\
\hline
\end{tabular}

Table 9. Operating Systems Tech

\begin{tabular}{c|c}
\hline Student & Section (Fall 2016 \\
\hline 1 & 91.6 \\
\hline 2 & 66.6 \\
\hline 3 & 97.7 \\
\hline 4 & 83.9 \\
\hline 5 & 81.5 \\
\hline 6 & 84.0 \\
\hline 7 & 83.6 \\
\hline 8 & 80 \\
\hline 9 & 80.7 \\
\hline 10 & 78.6 \\
\hline 11 & 60.7 \\
\hline 12 & 76.3 \\
\hline 13 & 96.5 \\
\hline 14 & 91.4 \\
\hline 15 & 95.3 \\
\hline 16 & 76.1 \\
\hline 17 & 89.3 \\
\hline 18 & 84.5 \\
\hline 19 & 83.4 \\
\hline 20 & 87.9 \\
\hline 21 & 91.9 \\
\hline 22 & 55.5 \\
\hline 23 & NA \\
\hline Avage & 82.6 \\
\hline
\end{tabular}




\section{NOTES}

